\title{
LAS LANZADERAS DE EMPLEO Y EMPRENDIMIENTO, INSTRUMENTOS INNOVADORES CONTRA EL DESEMPLEO: ASPECTOS JURÍDICOS Y DE POLÍTICA LABORAL
}

\author{
Jesús Esteban Cárcar Benito \\ Profesor Asociado de la Facultad de Ciencias del Trabajo de la Universidad de Murcia (UMU)
}

DOI: $10.1387 /$ lan-harremanak.15421

ABSTRACT

Las lanzaderas de empleo y emprendimiento suponen un cambio de enfoque en las politicas de inserción laboral desarrolladas hasta el momento. Representan una nueva filosofía en la intervención social del desempleo, llamando al cambio y a la acción, al trabajo en equipo comprometido y proactivo para que las personas desempleadas recobren la ilusión y descubran todas las competencias y habilidades que tienen para encontrar trabajo por cuenta ajena o para desarrollar su proyecto empresarial propio La nueva economia colaborativa y las lanzaderas de empleo, en particular, plantean cuestiones, a mi juicio, en dos ámbitos de la normativa laboral. Por un lado, el problema de la calificación de la relación de las lanzaderas con sus pares, aunque estas funcionen generalmente como intermediarios que instrumentan sus relaciones con sus usuarios como un acuerdo privado sin carácter laboral. En ocasiones, puede darse cierto grado de dirección y control por parte de los promotores, lo que abre la puerta a estimar que exista una relación con cierto nivel de dependencia y dirección. El segundo interrogante a abordar es si la prestación de servicios coadyuvantes por particulares no es realizada desde una estructura de negocio como la de una empresa o, directamente por la propia administración, habrá que categorizarla 
debidamente. Esta es una cuestión, a tener en cuenta, dado el carácter tuitivo de la normativa laboral. Este análisis intenta dar un itinerario sobre las cuestiones juridicas, económicas y de intervención laboral, politica laboral, para el empleo.

Palabras clave: Lanzaderas, sinergias, búsqueda de empleo, politica laboral.

The employment and entrepreneurship shuttles represent a change of approach in employment policies developed so far. They represent a new philosophy in social intervention in unemployment, calling for change and action, committed and proactive work team to unemployed people, who regain the hope and discover all the skills and abilities they have to find gainful employment or develop their own business project The new collaborative economy and employment shuttles in particular raise questions, in my view, in two fields of labor law. On the one hand, the problem of qualification of the relationship of the shuttles is with their peers, although they generally function as intermediaries that implement its relations with its users as a private agreement without a professional nature. Sometimes, there may be some degree of direction and control by promoters which opens the door to estimate that there is a relationship with some level of dependency and address. The second question to address is whether the provision of auxiliary services by individuals is not performed from a business structure like a company or directly by the administration itself, it should be properly categorize it. This is a question to consider, given the protective nature of labor legislation. This paper seeks to provide a route on the legal, economic and labor intervention issues, labor policy for employment.

Key Words: Shuttles, synergies, job search, labour policy. 


\section{Una introducción a la necesidad de actuación ante el problema del desempleo}

La crisis económica que sufre Espańa desde 2008 ha puesto de manifiesto las debilidades del modelo laboral espańol. Su gravedad no tiene precedente. Esta afecta a la situación en que se halla quien, siendo habitualmente trabajador por cuenta ajena y encontrándose apto para trabajar, ha de permanecer sin prestar sus servicios por causa independiente a su voluntad. Pero téngase en cuenta que junto al parado típico, el que ha perdido su trabajo, se halla el parado inicial, esto es, quien por falta de oportunidades no puede acceder a un primer empleo, pese a tener edad y capacidad para trabajar y deseo de hacerlo, paro que especialmente puede afectar a jóvenes que en efecto quieran y puedan trabajar. La destrucción de empleo ha sido más dura en ciertos colectivos, especialmente los jóvenes cuya tasa de paro entre los menores de 25 años alcanza casi el 50\% (2014).

Es innecesario recalcar la calamidad social que el paro implica por la frustración, la desesperación, la miseria y la pobreza que llevan consigo en todas partes largos períodos de desempleo; es posible que sean éstos los problemas sociales de más envergadura que plantea nuestra época. La Gran Recesión nos lleva a la admisión cada vez más general de que el desarrollo económico no conducirá por sí mismo a un aumento del empleo que debe, por tanto, ser buscado directamente - por ejemplo, encaminando las inversiones hacia donde se genere la máxima ocupación - como su fin en sí; en suma la creación de empleos es un factor esencial, en realidad el factor fundamental en la elevación de los niveles de vida. Todo lo anterior desde el punto de vista colectivo; si desde este pasamos al individual, se constata que la «amenaza del paro es la mayor opresión psicológica del trabajadon" (Benson, 1978), hasta el punto que se ha llegado a decir que tener empleo es símbolo de que se «ocupa un lugar entre los vivientes» (Neff, 1977).

La crisis ha dejado sin empleo a millones de ciudadanos que todavía están asimilando su nueva forma de vida tratando de adaptarse al momento económico que vivimos. Encontrar un empleo es vital para muchos. Ante la necesidad del empleo, nos acercamos al problema de su búsqueda. ¿Cómo resaltar entre cientos de candidatos para un solo puesto? ¿Revisan las empresas todos los currículos? ¿Por qué motivo los descartan? ¿Por qué en Infojobs (2014), el mayor 
portal de empleo en España, solo se anuncian 9.600 empresas cuando en España hay más de 600.000 compañías con más de tres empleados? Cada vez más candidatos y empresas se hacen estas preguntas.

El acceso al mercado de trabajo por parte de las personas desempleadas requiere también una formación que les facilite el camino. Enseñar a los que quieren integrarse en el mundo laboral, a veces por primera vez, apoyar a aquellos que han tenido que dejar su puesto de trabajo por imposiciones externas, lograr que quienes quieren cambiar de trabajo puedan hacerlo sin temor, forman parte de un proceso activo que se denomina búsqueda de empleo. El problema es: ¿Necesitamos un proyecto innovador dirigido a personas desempleadas de larga duración, en muchos casos jóvenes, que se convierten en agentes activos de su propio proceso de inserción laboral, con la ayuda de un coach-coordinador?, ¿necesitamos instrumentos eficaces para que nunca existan ocupaciones vacante que no sean ocupadas, pese a existir en paro trabajadores con capacidad para desempeñarlas, bien por falta real de información, bien porque se caiga en el desánimo y la falta de motivación?

\section{Una aproximación a la nueva economía colaborativa}

En un mundo cada vez más globalizado, donde las personas estamos interconectadas en la gran aldea global a través de las nuevas tecnologías y las redes sociales, y donde la internacionalización de empresas y trabajadores parece ser el paradigma del siglo xxI, se releva, en la situación de crisis económica global que venimos padeciendo, una nueva idea basada en el "trueque» tradicional aplicado al modelo 2.0, o denominada economía colaborativa. Las Tecnologías de la Información y la comunicación, en adelante TIC, después de impulsar el crecimiento de la productividad y de la economía en las últimas décadas sobre las bases de la vieja economía industrial están dando lugar a una nueva era económica en la que los viejos paradigmas irán perdiendo vigencia a favor de otros nuevos, que ya están comenzando a vislumbrarse. Las nuevas generaciones ya no podrán esperar como en el pasado que el Estado o las grandes empresas les resuelvan sus vidas; el trabajo y la financiación del «estado de bienestar» dependerán de cada uno y el emprendimiento individual — buscarse la vida - se extenderá cada vez más hasta proyectarse en un espacio mayoritario en la vida de todos los países.

La imparable emergencia de una nueva economía colaborativa, que está fuera de las grandes estructuras industriales que describiera Galbraith y de los costes de transacción que expusiera Coase y que se articula en torno a la satisfacción en tiempo real de las demandas individuales de los consumidores con 
apenas un click, está poniendo en cuestión las políticas laborales del pasado (Coase, 1960).

Sobre la base de estos nuevos rasgos, el intercambio de bienes y servicios se produce ya no entre profesionales, como era norma, sino a través de particulares y sin que dicho intercambio implique una actividad profesional remunerada por parte del oferente, aunque sí pueda existir un intercambio económico en razón de gastos compartidos o de pequeña compensación por la prestación de un servicios.

La era de la economía colaborativa supone un cambio de paradigma cultural en el que pasamos básicamente de una economía de propiedad y de tenencia a una economía de acceso. En este complejo y nuevo ecosistema una parte clave del mismo son los mecanismos de reputación. Estos dan al usuario que quiere acceder a un bien o a un servicio mayor información disponible sobre el bien o el servicio que va a consumir. En nuestro caso será el empleo.

La gente busca la transparencia, la eficiencia y el contacto humano (Galbraith, 2004). Además, las TIC darán una nueva dimensión al concepto de comunidad aplicado a los negocios. La reputación de una empresa o de una persona se convertirá en «la nueva moneda» Botsman (2010). Es posible afirmar: «si mi oferta laboral, nuestro currículo y motivación es mejor que la de otro par, otro candidato, pero mi reputación en esa plataforma no es buena, entonces la probabilidad de que yo sea quién encuentre trabajo es escasa por no decir nulas».

\subsection{La aplicabilidad de la economía colaborativa en el mundo laboral}

De todas estas formas de economía colaborativa interesan, desde el punto de vista del Derecho Laboral, aquellas que, en su caso, podrían conllevar implicaciones en este ámbito, concretamente las basadas en el intercambio de servicios. En algunos de estos casos, al pasar de la conexión on line a la vida off line, se pueden crear derechos y obligaciones jurídico-laborales entre los usuarios, o entre los usuarios y la empresa intermediaria en la plataforma digital creada para procurar ese intercambio de bienes y servicios. Ahora bien, el Derecho del Trabajo ha evitado, al menos por el momento, la plena mercantilización del trabajo subordinado, impidiendo que quede sujeto al gobierno o autorregulación por el mercado atribuyendo al trabajador el conjunto de los derechos de la ciudadanía que presupone que el rechazo del trabajo como pura mercancía con fundamento último en la dignidad humana (Monereo,1996).

Las pretensiones de los usuarios que, después de haberse puesto de acuerdo en una plataforma virtual creada al efecto, podrán ser intercambiar horas de trabajo, en lo que se denomina bancos de tiempo (hora por hora). Un usuario acoge a otro y a cambio le facilita una determinada formación para la búsqueda 
de empleo. La pregunta sería: ¿Son las lanzaderas la prolongación de la economía colaborativa?

Y, ciertamente, este es uno de los nuevos retos que plantea estas iniciativas de economía o trabajo colaborativo. Se trataría de determinar el intercambio de servicios verdaderamente colaborativos, de la prestación de servicios retribuida de carácter laboral. El ordenamiento jurídico-laboral, si bien no regula expresamente la denominada economía colaborativa, sí plantea otras figuras afines como los trabajos realizados a título de amistad, benevolencia o buena vecindad, excluidos del ámbito de la legislación laboral, de acuerdo con lo preceptuado en el artículo 1.3.d) del Estatuto de los Trabajadores (ET).

En estos trabajos, donde no se aprecian las notas típicas de una relación laboral (carácter retribuido, ajenidad y dependencia), lo que prima es el carácter desinteresado o colaborativo, y hasta cierto punto afectivo, del prestador del servicio o trabajo determinado, como ocurre, por ejemplo, con el voluntariado social, donde se realizan trabajos a título gratuito a favor de personas que lo puedan necesitar en un momento determinado (ej. Voluntarios de Cruz Roja). El propósito de los servicios prestados a la par, no es el lucro económico, ni siquiera la formación profesional, sino la transversalidad, e intercambio personal que supone el conocimiento de otras experiencias.

Así, en todos estos casos, y salvo constatación de la concurrencia de las notas clásicas de ajenidad y dependencia propias de una relación laboral, estaríamos ante relaciones fuera de la legislación laboral, excluidas del sistema, por entenderse residuales, sin retribución alguna y sin fin de ganancia.

El razonamiento es: ¿Cómo puedo llegar a más empresas para busca empleo?, ¿cómo empoderar y dar valor a los usuarios una nueva plataforma para encontrar puestos vacantes?, ¿cómo puedo generar una cultura homogénea del servicio que se está ofertando cuando el desempleado no controla la oferta y menos aún tiene experiencia?, ¿cómo se genera confianza entre los demandantes de empleo? En definitiva, la pregunta clave será: ¿Cómo hacer comunidad para la prospección de empleo?

En ocasiones, incluso sin retribución, se ha entendido que existía relación laboral, donde lo que se estaba incumpliendo era la obligación de retribuir la prestación de servicios y la obligación de dar de alta y cotizar en la Seguridad Social con carácter retroactivo por el usuario-trabajador, con los recargos procedentes; afrontar las retribuciones que no hubieran sido satisfechas de acuerdo con la legislación y convenio colectivo aplicable, en su caso; y una sanción administrativa por comisión de una falta calificada como grave (Lujan, 1994).

En efecto, partimos de la incertidumbre de un modelo económico dinámico en su desarrollo y dispar en su conceptualización, pues estamos ante proceso que genera grandes incoherencias debido a los múltiples proyectos con ba- 
ses diferentes que están compartiendo o apropiándose del concepto colaborativo (Paniagua, 2015). Los sectores tradicionales, sujetos de la búsqueda de empleo, en muchos casos, sometidos a una regulación estricta y extensa y a unos costes de operación nada desdeñables, han visto con impotencia como la aparición de diferentes plataformas on-line les enfrentaba a un nuevo tipo de competencia. Existen, por tanto, formas disruptivas que no equivalen a negativas, claramente beneficiosas para el global de la economía y de la sociedad. Debido a esta situación hay una necesidad de iniciar un proceso de reflexión abierta sobre este nuevo instrumento que son las lanzaderas.

\section{Las lanzaderas de empleo y la búsqueda de empleo colaborativo}

Una Lanzadera de Empleo y Emprendimiento Solidario es un proyecto innovador dirigido a personas desempleadas de larga duración, en muchos casos jóvenes, que se convierten en agentes activos de su propio proceso de inserción laboral, con la ayuda de un coach-coordinador. Una lanzadera es, por tanto, un equipo heterogéneo de personas desempleadas con iniciativa, dentro de un compromiso solidario que acceden de forma voluntaria y que son oportunamente coordinadas. Conviene señalar que sus competencias, generan conocimiento colectivo, se hacen visibles y colaboran en la consecución de un fin común: conseguir empleo, ya sea por cuenta propia o ajena. El dibujante, arquitecto y presidente de la Fundación de Santa María la Real, José María Pérez González, el conocido Peridis, impulsó esta iniciativa a partir de su experiencia con las escuelas taller. Observó que los participantes de los talleres aumentaban su autoestima trabajando en ello. A diferencia de los desempleados, ante la falta de expectativa de colocarse y, sobre todo, al sentirse abandonados por parte de la sociedad, caían en la desesperanza (Fundación Santa María La Real, 2013).

No es necesario señalar que ha existido un recorte en políticas activas de empleo para personas en paro, ante lo cual no cabe la resignación. Las cuestiones girarían sobre si existe el rescate mutuo. ¿Qué surge de la experiencia colaborativa? ¿Estamos ante un método de trabajo?

Las lanzaderas funcionan en torno a una estructura formada por personas voluntarias desempleadas (entre 15-20), con distinta cualificación y formaciones complementarias, dispuestas a trabajar en equipo para conocer las posibilidades del mercado laboral, mejorar su empleabilidad y ayudarse mutuamente para encontrar trabajo, montar sus propios proyectos y desarrollar sus competencias profesionales y personales. La solución aportada tiene dos rasgos: en primer lugar, la labor del coach consistente en la detección del talento, los valores y las competencias necesarias entre los candidatos a participar en la lanzadera durante 
el proceso de selección; en segundo lugar, en crear el espacio y facilitar las condiciones necesarias para que la competencia salga a la luz.

La formación que el desempleado requiere tiene que ver con las competencias transversales, claves para las empresas hoy, como son: inteligencia emocional, trabajo en equipo, comunicación, gestión del tiempo, marca personal, herramientas 2.0, así como formación práctica en emprendimiento. En el mercado laboral, el desempleado necesita asesoramiento en la búsqueda de oportunidades laborales, capacitación o la presentación de currículum. Por tanto, una lanzadera es un equipo de desempleados voluntarios, visibles, activos y solidarios, que se reúnen casi todos los días, organizándose por departamentos como una empresa y que buscan trabajo todos para todos, preparándose activamente y haciendo intermediación laboral.

La lanzadera se basa, por tanto, en una figura que carece del animus obligandi dentro de lo asistencial. Es un lugar de razones profundas, de antropología social en el siglo xxi. Es decir, lo que Dworkin llamaba comunidades meras, simples o íntimas, no ligadas por pactos asociativos explícitos (Fried, 1981: 25). La iniciativa de lanzaderas de empleo y emprendimiento solidario surgen, en consecuencia, como una alternativa, dentro de lo que se denomina jurídicamente buena vecindad o contrato de intercambio de servicios (Bayón Chacón, 1957) para la inserción laboral de los desempleados. Estamos ante personas colectivas (asociaciones, corporaciones fundaciones) y un organismo social autónomo, dando forma a un cuerpo que es la colectividad de individuos erigida en la realización de una voluntad unitaria, la búsqueda de empleo.

\subsection{El modus operandi de las lanzaderas: personas unidas para conseguir trabajo}

Cada equipo se reúne durante cinco o seis meses con el objetivo de ayudar a sus compañeros a conseguir un empleo y de recibir el mismo apoyo por parte de estos. Los participantes se encargan de ir a las empresas, conseguir entrevistas y poner a la lanzadera en contacto con los responsables y directivos de las organizaciones para conocer qué puestos de empleo podrían ocupar. También las propias empresas se acercan a ellos para informarles sobre qué tipo de perfiles pueden encajarles mejor según las necesidades. Cuentan con la ayuda de un coach, como he indicado, para coordinarlos. Este les apoya y dirige las sesiones grupales e individuales en las que trata de averiguar cuál es la vocación de cada persona, en qué ha trabajado, qué le gustaría hacer.

El objetivo de la lanzadera es asistencial con un sentimiento de altruismo dentro del afecto, el conocimiento y el tiempo dedicado. Y este es otro enfoque radicalmente distinto a lo que hace un Servicio de empleo, un ámbito más personalizado y respetuoso. En ellas participan personas de todos los sectores, pero se intenta que no coincidan varios miembros de la misma área en una lanzadera para que no compitan por el mismo tipo de trabajo. 
En cuanto a los tipos de empleos que consiguen los participantes, debe haber absoluta transparencia, en la web se pueden ver las fichas de todos los participantes con sus correspondientes fotografías y currículos además de a qué lanzadera pertenecen. Además un requisito es la exigencia de una evaluación del impacto en el que tiene que participar en la iniciativa sobre la persona y sobre su entorno.

Esto no exime de la participación de varias entidades privadas (la Fundación Telefónica, Barclays, La Caixa o Caja Burgos, etc.), además de comunidades autónomas, que podrían conseguir nuevos apoyos institucionales. Una lanzadera debe establecerse dentro de una institución, promotor, sin ánimo de lucro cuya misión consiste en generar desarrollo económico, social, personal y profesional, a partir de diversas actividades y que, en ese marco, impulsa la inserción laboral por medio de talleres de empleo y otros programas de formación.

El ente promotor debe comprometerse a implantar las lanzaderas de Empleo y Emprendimiento. Para ello, aportará el conocimiento acumulado y desarrollado en las experiencias de lanzaderas anteriores y concretamente desarrollará, entre otras, las funciones siguientes: a. definición metodológica del proyecto y aseguramiento de su cumplimiento; b. definición del perfil, selección, formación y contratación del futuro coordinador/a de lanzaderas; $\mathrm{c}$. formación de un técnico, no siempre del Servicio regional de empleo, que realizará las funciones de asistente del coordinador de las lanzaderas seleccionado, y que posiblemente recoja el testigo; d. apoyo en la selección de los participantes; e. diseño del plan de comunicación de la lanzadera y gestión de la comunicación general del mismo en el marco del proyecto; $f$. seguimiento, control y evaluación del proyecto.

\subsection{El papel de los Servicio de empleo y el apoyo a las lanzaderas}

No se puede reducir el papel de la Administración laboral a una función pasiva certificante de una realidad lacerante, el desempleo, como situación preexistente, y caer en el reconocimiento. Ahora bien, los Servicios regionales de empleo y formación deben contribuir activamente, y realizar programas de apoyo a la economía real, creando las condiciones para la consolidación de un modelo productivo que garantice el empleo de calidad, digno y estable. Tendrían que comprometerse a incluir el proyecto de lanzaderas dentro su cartera de servicios, facilitando a los participantes el acceso a dichos servicios. Es decir, colaborar en la difusión del proyecto y apoyar en la captación y selección de participantes como una prolongación del apoyo al empleo y/o el emprendimiento. Además, deberían poner a disposición un espacio para desarrollar las sesiones de equipo, preferiblemente en horario de mañana, de lunes a viernes. Dicho espacio tendría capacidad para los miembros de la lanzadera, al menos, 21 personas (20 partici- 
pantes + el coordinador/a), para sesiones que tendrán una duración aproximada de 4 hora y deberá contar con elementos didácticos pizarra, conexión a Internet y, al menos un número suficiente de equipos informáticos que estén operativos y que puedan conectarse a la red. Por último, la lanzadera requiere un despacho/espacio para que el coordinador pueda desarrollar las sesiones individuales con los participantes y dar continuidad al proyecto.

Es de destacar que la institución pública, además pondría a disposición del proyecto un técnico que colaboraría como asistente con el coordinador seleccionado del proyecto, y que a su vez transmita los principios y la metodología en la que éste se basa. Es decir, aceptar la metodología desarrollada y facilitar la actividad de gestión y supervisión del ente promotor de la lanzadera, de tal forma que pueda desarrollar adecuadamente sus compromisos. Repárese en que hay un requerimiento de dar información a los trabajadores interesados en la sede donde se desarrollen las lanzaderas, reservándose la posibilidad, ocasionalmente, de supervisión de las actividades realizadas durante el proyecto.

\subsection{El problema de la marca de los entes colaborativos participantes}

Debe existir una información pública de la existencia y ejecución de la actividad, de manera leal y respetuosa, los signos distintivos de la otra o las fotografías o nombres de los empleados y/o representantes de la otra. En todas las comunicaciones del proyecto, deberían recogerse el logo del ente promotor de la lanzadera. En la ejecución el proyecto, se habilitaría el poder suficiente para permitir a las diferentes instancias intervinientes la utilización de los referidos signos distintivos, nombres, derechos de imagen, o cualquier otro bien protegido por las normas en materia de propiedad industrial e intelectual y derechos de imagen.

La utilización de los signos distintivos deberá hacerse conforme al formato que, al efecto, facilitaría la titular o que se exhiba en su página web y siempre sin alterar o modificar su aspecto y exclusivamente para los fines previstos. En caso de utilización de los signos distintivos o imágenes junto con otro ente interviniente (por ejemplo, en páginas web, artículos, memorias o catálogos), no debería existir un riesgo de asociación o confusión indebida.

Los entes promotores podrán informar públicamente y siempre de modo leal de la existencia y cumplimiento de los acuerdos colaborativos, en la medida y medios que consideren oportunos. Asimismo, divulgarán del modo que estimen más conveniente y siempre de manera leal, los resultados de las actividades. Deberán informar a la otra parte de ello, antes de la publicación en caso de que esta pueda tener particular relevancia. A tal fin, siempre habrá una copia del texto completo e imágenes de la otra, que no denegará su consentimiento de manera irrazonable. En caso de no obtener respuesta a la comunicación, la autorización se entenderá concedida. 


\section{El problema jurídico del vínculo}

En este contexto, habría que analizar el vínculo del grupo y las tareas realizadas en la lanzadera. ¿Dónde podemos incluir jurídicamente las tareas y trabajos que realizan los miembros de la lanzadera? Los trabajos prestados amistosos o benévolamente no constituyen contrato de trabajo, ni probablemente contrato alguno, al faltar el animus obligandi, tanto quien recibe los servicios como en quien los promete o presta (Alonso Olea, 2000). A ellos se asimilan los denominados servicios «de buena vecindad» o "contrato de intercambio de servicios» (Bayón Chacón, 1957), asimilación reiterada por la jurisprudencia Pero puede haber ayudas y servicios de buena vecindad sin intercambio, y quizás sea en ellos precisamente en los que está pensando el art.1.3.d) ET.

El art. 1.3.d) ET no ofrece un concepto de trabajos amistosos, benévolos o de buena vecindad, sino que se limita a excluirlos de la normativa laboral. De la redacción legal no se desprende con claridad si el legislador pretende diferenciar tres clases de actividades, o si se trata de una sola actividad, que podría calificarse como trabajo altruista. La práctica ha demostrado que aunque se utilicen como sinónimos, pueden distinguirse los trabajos amistosos de los benévolos, y cualquiera de ellos tiene caracteres diferentes a los trabajos de buena vecindad, si bien es claro que los trabajos de buena vecindad pueden realizarse también por motivos de amistad (Blat,1990).

En todo caso, la amistad, la benevolencia o la buena vecindad entre quien presta el servicio y quien lo recibe no conlleva necesariamente una deslaboralización de la prestación de servicios, pues la relación laboral nace cuando concurren todas las notas del trabajo asalariado. Desde luego, quien presta servicios para un amigo o un vecino de forma voluntaria, dependiente, retribuida y por cuenta ajena se encuentra protegido por el Derecho del Trabajo, y consecuentemente también por el Sistema de Seguridad Social. De este modo, el art. 1.3.d) ET establece una exclusión meramente declarativa, puesto que los trabajos a título de amistad, benevolencia o buena vecindad no generan derecho a contraprestación económica, y por ello no es menester norma expresa que los excluya de la legislación laboral.

La ausencia de retribución se presenta a priori como un elemento definitivo, sin perjuicio de la percepción de alguna cantidad como compensación por gastos. Es claro que si media contraprestación económica que retribuya el trabajo rige como pauta la presunción de laboralidad (Mella,2001) contenida en el art. 8.1 ET, en virtud de la cual el contrato de trabajo «se presumirá existente entre todo el que presta un servicio por cuenta y dentro del ámbito de organización y dirección de otro y el que lo recibe a cambio de una retribución» (Bayón Chacón, 1957). Este podría ser el caso del coaching, si es retribuido; el trabajo amistoso de los demás miembros, por tanto, cuenta con carácter excepcional, 
aunque se requiere una comprobación casuística. Deben ser las propias partes, y fundamentalmente quien se beneficie del servicio, las que destruyan esa presunción, pues de lo contrario se presume que ese trabajo es asalariado. Por el contrario, la presunción del art. 8.1 ET no entra en juego si no hay indicios de laboralidad, situación que acontece, por ejemplo, cuando no se ha probado la existencia de retribución; a la postre, el art. 8.1 ET no contiene una auténtica presunción desde el momento que requiere que estén presentes todos los elementos que configuran un contrato de trabajo.

¿Qué son las lanzaderas de empleo jurídicamente hablando? La benevolencia del trabajo es independiente de la del empresario al que se presta; a un ente benéfico sin ánimo de lucro directo, en donde se pueden prestar trabajos contractuales y remunerados; y viceversa (Alonso Olea, 1997:60). El trabajo amistoso, benévolo o de buena vecindad cuenta con referencias legales, pero son alusiones de carácter residual, destinadas principalmente a estudiar el alcance de la legislación laboral. En los últimos años, no obstante, una modalidad de ese tipo de trabajos, el llamado voluntariado social, ha ido adquiriendo progresivamente una extensión, hasta el punto de merecer regulación específica. Se ha convertido en una institución con identidad propia que ha desbordado el marco del trabajo amistoso, benévolo o de buena vecindad, y que cuenta con un régimen jurídico previsto legalmente, tanto a nivel estatal - Ley 45/2015, de 14 de octubre, de Voluntariado-, como autonómico.

La tradicional exclusión del trabajo amistoso, benévolo o de buena vecindad de las normas laborales y de Seguridad Social se explicaba por su propia naturaleza, en la medida que no era más que una manifestación de la ayuda esporádica $\mathrm{u}$ ocasional que se prestaba a un pariente, vecino o amigo que en un momento dado lo requería. El vínculo de afectividad entre las partes justificaba esa exclusión.

Sin embargo, al relacionar la Ley 45/2015 se observa que la exclusión del ordenamiento laboral de los trabajos relacionados en el art. 1.3.d del ET carece de un animus obligandi bilateral, procedente tanto de quien presta el servicio como de quien lo recibe. No es esta, sin embargo, ante una conclusión que pueda predicarse de la actividad de voluntariado, en la que tanto el voluntario como la entidad con la que colabora y en la que se integra asumen, como se encarga de declarar el art. 7.1.a LV, un "conjunto de derechos y de deberes», que es el que «corresponde a ambas partes». Precisamente, el instrumento encargado de recoger esos derechos y deberes es el denominado por la propia LV «•acuerdo o compromiso» de incorporación» (Valdés Dal-Ré, 2012).

Las lanzaderas de empleo pueden ser entendidas, por tanto, como una manifestación de benevolencia, una forma de trabajo solidario, entendida la solidaridad como una actitud de apoyo activo hacia los problemas de personas necesitadas, los desempleados jóvenes. La presencia de la organización hace natural 
para el interviniente voluntario, que sean reembolsados los gastos realizados (que no remunerados los servicios prestados) por el voluntario en el desempeño de sus actividades, así como se provea su aseguramiento por la organización contra los riesgos de accidente y enfermedad "derivados directamente de su actividad" (Alonso Olea, 1997:60).

Estamos ante una iniciativa, la lanzadera, con un papel en el diseño y ejecución de actuaciones dirigidas a la satisfacción del interés general y especialmente a la erradicación de situaciones de marginación, como es el desempleo, y a la construcción de una sociedad solidaria en la que todos los ciudadanos gocen de una calidad de vida digna. El problema es la forma jurídica categorial, la juridificación de lo colectivo se inserta también es esta estrategia político-jurídica de «desmercantilización» relativa del trabajo abstracto ( $\mathrm{y}$ de la subjetividad jurídica abstracta correspondiente) a través de las garantías constitucionales de un principio de autogobierno colectivo (Monereo, 2004). La lanzadera no es un ser social abstracto, sino una comunidad social aglutinante sobre una base de realidad social formada por un conjunto de individuos agrupados para determinados fines comunes, como es la búsqueda de empleo. Habría que penetrar, por tanto, desde el principio de colaboración y definir la participación de todos los sujetos que la integran siendo participes activos.

\section{La cuestión del emprendimiento y la lanzadera}

Quedaría aún por decir, para concluir el problema de encuadre jurídico de la lanzadera dentro del emprendimiento y si la Ley 14/2013, de 27 de septiembre de apoyo a los Emprendedores y su internacionalización [BOE »núm. 233, de 28 de septiembre de 2013, páginas 78787 a 78882] es aplicable, en cierta medida, al fomento de la actividad en la búsqueda de empleo. Esto requiere hablar de la eficacia de las políticas de apoyo institucional al emprendimiento, que abarcan todas aquellas iniciativas públicas que ofrecen servicios de asistencia, información, asesoramiento y fomento de la cultura emprendedora o impulsan la prestación de estos servicios con carácter privado a través de esquemas de colaboración.

Desafortunadamente, desde la perspectiva puramente mercantil, la norma citada no es sólo incompleta, por no haber abordado las cuestiones que hubieran impulsado verdaderamente la iniciativa empresarial, sino que introduce una serie de cuestiones cuya aplicación pueden resultar incluso perjudiciales para la promoción económica mercantil. Se trata de una norma compleja y transversal, por razón de las materias que incluye, por lo que nos centraremos en su contenido en el ámbito docente y formativo y en el mercantil, dejando al margen las cuestiones fiscales, de derecho laboral o de seguridad social y administrativas. 
El marco legal del emprendimiento podría llevar a pensar si la lanzaderas reflejan lo normado sobre el emprendimiento Pues bien, desde la perspectiva de los principios generales y el ámbito docente, la Ley de Emprendedores diseña las bases de una formación y enseñanza de y para el «emprendimiento», de modo que los artículos 4, 5 y 6 (Capítulo I, del Título I) de la Ley delimitan la denominada "Educación en emprendimiento». La Ley de Emprendedores, en sus artículos 4 a 6 , sienta unos principios generales de «educación en emprendimiento", basados en la promoción del espíritu emprendedor y las iniciativas de emprendimiento en la enseñanza primaria, secundaria y universitaria, así como entre el personal docente (J\&A. Garrigues, 2013) Es decir, la estimulación del espíritu emprendedor a través de la posibilidad de elección de las trayectorias educativas más adecuadas y de la creación de las condiciones para que todos los alumnos puedan adquirir y expresar sus talentos. En este sentido, el artículo 5 de la precitada Ley recoge el objetivo de acercar la Universidad a la Empresa y viceversa, objetivo que requiere verdaderas iniciativas y medidas prácticas tendentes a ello, más que principios programáticos por todos compartidos. Pero lo que quizás produce un impropio sentido, es la denominada «formación del profesorado en materia de emprendimiento" ¿En qué consiste dicha formación? ¿Cómo piensa desarrollarse? ¿Significa eso que el «emprendimiento» ha de pasar a ser un conocimiento transversal incluido en cualquier titulación universitaria? ¿Podemos encuadrar las lanzaderas como un procedimiento para el emprendimiento?

En fin, en la Ley hay una manifestación del profesorado universitario como reflejo fáctico del coach: ¿se puede asimilar la actividad del profesor con el coaching? Sin perjuicio de lo anterior, la Ley recoge una medida de «innovación docente», que a día de hoy, en uno u otro formato, ya estaba siendo aplicada y desarrollada por alguna Universidad. El objeto es garantizar que el fracaso no cause un empobrecimiento y una frustración tales que inhiban al nuevo empresario de comenzar un nuevo proyecto y pase a ser un medio para aprender y progresar.

A través de las denominadas "miniempresas» o "empresas de estudiantes», que están previstas en la Disposición Novena de la citada Ley, hay una apelación a la siguiente discriminación. Es trasladable a una organización empresarial, pero en el ámbito de la actividad docente y formativa universitaria implica un mecanismo formativo de colaboración Universidad-empresa. Ahora bien, desde la perspectiva jurídica mercantil, supone una modalidad específica de actividad empresarial desarrollada, aparece — sin constitución de sociedad mercantil alguna-, de modo que la actividad empresarial, que se reconoce es una herramienta pedagógica. La miniempresa no tendrá personalidad jurídica propia y distinta de los estudiantes que la integren, lo que no es óbice para que fiscalmente pueda emitir facturas y actuar como tal con "cierta personalidad jurídica» (a modo de comunidad de bienes) (Muñoz, 2015). 
El artículo 3 de la citada Ley, define a los emprendedores como «aquellas personas, independientemente de su condición de persona física o jurídica, que desarrollen una actividad económica productiva, en los términos establecidos en esta Ley». Es decir, se opta por identificar al emprendedor como todo sujeto que desarrolla una actividad económica productiva, desconectando o desvinculando dicha definición del concepto mercantil de empresario, de tal forma que podrá haber emprendedores no empresarios, cuando en ellos, pese a realizar una actividad económica o profesional, no concurran los elementos propios de la actividad empresarial (organización fundamentalmente), pero todo empresario debería ser siempre un emprendedor, al amparo de la conceptualización expuesta, aunque se trate ya de una actividad empresarial consolidada. Parece que dicha definición normativa en la medida en la que no engloba adecuadamente al fenómeno del emprendimiento que se encuentra, vinculado a fases iniciales de la actividad económica o empresarial, necesitadas de especial impulso, no parece abarcar correctamente esta iniciativa. Ahora bien, más allá de esta disquisición, la definición conceptual carece de problemas prácticos, siempre y cuando se tenga clara su diferencia con el concepto de empresario, dado que la calificación como emprendedor en el ámbito mercantil en concreto no conlleva per se consecuencia alguna.

En conclusión, el emprendimiento nos sirve para fijar las lanzaderas desde el punto de vista de la categorización de lo mercantil, en la línea de separación entre el impulso real y eficiente de la actividad empresarial, y dentro de la misma, en su fase de iniciativa y la de creación. Existe, por ello, el grave peligro de confundir lo uno con lo otro. Parece que la Ley de Emprendedores ha caído en dicha confusión, de modo que se ha perdido una ocasión para impulsar de manera efectiva los nuevos instrumentos de la iniciativa empresarial o laboral.

\section{La parte sinérgica de la lanzadera dentro de la búsqueda de empleo}

La sinergia que se crea entre las personas es una primera ventaja evidente de las lanzaderas. Además, se produce el aprendizaje entre pares, imposible a solas con un orientador/a (se aprende mucho contemplando los aciertos y errores del que tenemos al lado). Se genera también un refuerzo de la motivación (Carbo, 1995), el aspecto más complicado de trabajar en sesiones individuales. En el grupo las personas se ven reflejadas y se sienten identificadas con las realidades de los demás, se generan unas relaciones de compañerismo y de apoyo mutuo que empujan a seguir adelante.

Desde el punto de vista del operativo supone: participar en sesiones individuales y grupales de "coaching», trabajar la inteligencia emocional, la comunicación y la creatividad. Los intervinientes conocerán nuevas técnicas de 
elaboración y presentación de currículos, analizarán cómo afrontar las entrevistas de trabajo, desarrollarán mapas de empleabilidad y aprenderán a trabajar la marca personal, a diferenciarse y a posicionarse mejor en el mercado laboral. También abordarán la búsqueda de oportunidades de negocio y los pasos a seguir para crear empresas. Todo ello con un único objetivo: encontrar trabajo.

Los proyectos de búsqueda de empleo en grupo hacen hincapié en la motivación, el empoderamiento y la autonomía de sus participantes. Por una parte, porque es uno de los fuertes del trabajo en equipo, pero también porque se hace necesario después de tanto tiempo en crisis y en una situación de desempleo tan complicada como la que tenemos. Quien ha sufrido las consecuencias de un paro, a veces muy largo, puede estar demasiado desmoralizado e inmotivado para hacer el esfuerzo necesario para volver a trabajar (Neff, 1977: 35). Deben existir nuevos ánimos para seguir en la búsqueda y el grupo nos puede apoyar en eso.

Además, se pone el énfasis en los protagonistas de la iniciativa, que son las personas que conforman el grupo. Cuando se habla de las técnicas de estos proyectos, se les llama coach, facilitadores, acompañantes, etc., posicionándoles como un elemento de apoyo. No se trata de dirigir ni de orientar ni de coordinar, sino de "facilitar» la generación de procesos de autoconocimiento individual y grupal, coach. Se trata de dar protagonismo a las personas desempleadas para que se conviertan en los actores principales de su proceso de búsqueda de empleo (CCOO, 2013).

El establecimiento de metas y objetivos es fundamental para el buen desarrollo de cualquier proyecto, personal o profesional. Por eso debemos dedicarle el tiempo que sea necesario para que quede claramente definido (Lujan, 1994). Supone el conocimiento de los peldaños que necesitamos seguir para buscar un puesto de trabajo, conocer las herramientas de búsqueda, dónde dirigirse y de qué forma hacerlo no es suficiente para conseguir un empleo. Este conocimiento no es motivador en sí mismo, de hecho muchos desempleados saben qué "tienen que» hacer para buscar trabajo y sin embargo en un momento dado tiran la toalla. Lo que realmente motiva a las personas, sean o no desempleadas, es tener clara su meta profesional, en qué y de qué quiere trabajar es decir sus objetivos laborales.

Las lanzaderas son la orientación laboral ante personas que no saben de qué quieren trabajar. La respuesta de "en cualquier cosa» se convierte en la respuesta fáctica y tópica reiterada que les lleva a realizar búsquedas desorientadas, sin objetivo claro, dando palos de ciego que lo único que generan a la larga es dejación, frustración y abandono. Sin embargo, los profesionales de la orientación, los coach, van en la línea de la obligación de centrar su búsqueda analizando su $\mathrm{CV}$ y en base a ello indicar a los dirigidos donde "pueden» trabajar. A veces, hay 
un olvido de lo que se quiere (Nebot, 1999). Por eso es esencial comenzar con el establecimiento de objetivos, porque la intervención debe realizarse con el análisis de la realidad (analizando su CV). Es decir, comenzar desde una tendencia a condicionar las metas que dejarán de ser las que realmente quieren y desean (Jackson, 1995).

La meta de la lanzadera está asociada a un fin, tiene que ver con el objetivo final y pocas veces está bajo el control absoluto de uno. También puede haber una meta profesional, pero su consecución no depende únicamente de nosotros, desconocemos las ofertas laborales existentes, el número de candidatos, su preparación, etc. Es necesario articular ese final goal (meta u objetivo) asociado a un fin en objetivos más pequeños, es decir, descomponer la meta en conductas más pequeñas, que dependen exclusivamente de uno y que por tanto motiven la acción.

Estos objetivos menores son los denominados objetivos de rendimiento. Si queremos que estos objetivos de rendimiento cumplan un papel activador en el sistema motivador deben cumplir, al menos uno de los siguientes requisitos: ser auténticos. El trabajo del orientador, coach, consiste en aplicar determinadas técnicas que permitan al desempleado plantear sus propias metas. Hay que asegurar que es la propia persona desempleada la que decide y asume qué actuaciones son esas y cómo desarrollarlas

Tiene que existir una estrategia en positivo. Un objetivo motivador debe formularse como algo a hacer o a conseguir (Podesta y Gatz, 1999). No como al abandono de una actividad. Los objetivos en positivo son motivadores porque ayudan al desempleado a imaginarse en una situación de cierto éxito, de logro, aunque sea parcial. Además de estos deben poseer determinadas cualidades para poder catalogarse como objetivos smart, otro término inglés que significa «inteligente» en la consecución y que al igual que grow, crecimiento en las competencias. En definitiva, lo que se persigue con esta iniciativa es un cambio de mirada y de actitud, que la persona desempleada abandone la desgana o desilusión, que descubra todas las competencias que tiene para ser útil, ayudar a los demás y encontrar trabajo.

Hay otro aspecto importante que se pone de manifiesto con estas iniciativas: el trabajo colaborativo. Las empresas aprecian cada vez más a personas que puedan trabajar con otros en una cultura colaborativa, conscientes de que el trabajo en red es mucho más productivo a largo plazo. El trabajo individual es más sencillo, menos conflictivo, pero tiene también menos alcance. Un trabajo realmente colaborativo implica mayor esfuerzo, dedicarle más tiempo y mucha flexibilidad, pero sus resultados son más creativos, innovadores, profundos y duraderos. Es decir generar un buen trabajo en equipo, basado en la cooperación. 


\section{Algunas conclusiones}

En las lanzaderas, la consideración de los aspectos personales y del entorno de las personas que buscan trabajo es fundamental en el desarrollo de las distintas acciones de política activa y de orientación laboral a desarrollar, individualizando y personalizando. El asesoramiento e información que reciban en función de las necesidades particulares favorecen las posibilidades de inserción en el mercado laboral, en las condiciones más acordes con sus propias actitudes y aptitudes personales.

Los Servicios públicos de empleo, en la mayoría de los casos, llegan a la ciudadanía, pero no consiguen que sus objetivos profesionales calen en los individuos, no tienen penetración. Si bien ofreciéndoles información actualizada, colaboran en la planificación de la inserción, las lanzaderas radican en la individualidad: entrenándoles en las habilidades instrumentales Es decir, adaptarse al usuario y facilitarle las herramientas que hagan posible la búsqueda autónoma de empleo o la colocación por cuenta propia. Por todo ello, considero que las lanzaderas de empleo responden a los siguientes rasgos: 1. La individualización en las lanzaderas que debe consignar las necesidades y circunstancias de cada participante. Por tanto, los contenidos, la temporalización, el lenguaje y las técnicas a utilizar deberán adaptarse a cada persona.; 2. La flexibilidad que debe permitir los ajustes necesarios provocados por nuevas situaciones, actividades y/o informaciones que incorpora y realiza la o el usuario. Asimismo, permitirá una intervención tanto individual como grupal cuando se considere conveniente, adaptando dichas intervenciones a los casos concretos. 3. El desarrollo/búsqueda en la actividad de la lanzadera debe potenciar la autonomía de cada participante, desarrollando sus recursos, habilidades y competencias.

La intervención que suponen las lanzaderas consta de cuatro elementos básicos, a mi juicio: 1 . Un encuadramiento dentro de la economía colaborativa de la atención/intervención individual y resultado grupal. La conceptualización jurídico laboral es próxima a los trabajos amistosos, benévolos o de buena vecindad, sin desdeñar las notas de voluntariedad y emprendimiento; 2. Un «sistema facilitador de inserción» que ordena y relaciona las principales materias o contenidos que configuran la tarea de los orientadores, coach; 3 . Una estrategia general de intervención con las personas que buscan empleo, que podríamos llamar "centrada en los recursos del usuario», que puede adaptarse a un servicio público de empleo por su carácter positivo y breve; 4. Itinerarios de aprendizaje basados en una metodología en la que la persona es la protagonista y que tiene como objetivo que se responsabilice de su propio proceso. Todo ello representa una variedad en la intervención social, que supone la política laboral, contra el desempleo, llamando al cambio y a la acción, al trabajo en equipo comprometido y proactivo para que las personas desemplea- 
das recobren la motivación y descubran todas las competencias y habilidades requeridas para encontrar trabajo por cuenta ajena o para desarrollar su proyecto empresarial propio.

Las lanzaderas tratarían precisamente de poner límites a la puesta a disposición del trabajador donde queda inevitablemente la persona que aspira a un puesto de trabajo. Contrarrestarían esa relación contractualista y patrimonialista de la asimilación del trabajo a un bien mercantil, y contendrían los procesos de liberalización excesiva en la etapa de incorporación al empleo.

\section{Bibliografía}

Alonso Olea, M. \& Casas Bahamonde, E. (1997): Derecho del Trabajo, Decimoquinta edición, Civitas.

- (2000): «Trabajos amistosos, benévolos o de buena vecindad. Trabajos familiares», REDT, n. ${ }^{\circ} 100$, Tomo I , pp. 83 ss.

Bayón Chacón, G., (1957): «El contrato de intercambio de servicios», Revista de Derecho del Trabajo, n.o 21.

Benson, L. (1978): Proletrians and parties, Londres, p. 124.

Blat Gimeno, F. (1990): «Trabajos amistosos», en E. Borrajo Dacruz (dir.), Comentarios a las leyes laborales. El Estatuto de los Trabajadores. Tomo I, EDERSA, Madrid, 1990, pp. 155 y ss.

Bostman, R.; Rogers Roo (2010): What's Mine Is Yours: The Rise of Collaborative Consumption?, Harper Business, October.

Carbo, E. (1999): Manual de Psicología aplicada a la empresa, Granica, Barcelona.

Coase, R.H. (1960): «The problem of social coast», The Journal of Law and economics, Universiry of Virginia Vol III, n. ${ }^{\circ}$ October 1960.

Comisiones Obreras (2013): Guia Amarres Solidarios. http://www.extremadura.ccoo.es/ comunes/recursos/10/1963124-

Fried, Ch. (1981): Contract as a promise, Harvard University, p. 25.

Galbraith, J.K. (2004): La economía del fraude inocente: la verdad de nuestro tiempo", Critica.

González Ortega (1990): «La presunción de existencia del contrato de trabajo», en A. Montoya Melgar, A. Martín Valverde y F. Rodríguez-Sañudo Gutiérrez (coord.), Cuestiones actuales de Derecho del Trabajo. Estudios ofrecidos por los catedráticos españoles de Derecho del Trabajo al profesor Manuel Alonso Olea, MTSS, Madrid, 1990, pp. 802 ss.

J\&G. Garrigues (2013): Ley 3/2013, Novedades-Garrigues, Octubre.

Jackson, T. (1995): El currículum perfecto, Playor, Madrid.

Luján Alcaraz, J. (1994): "La contratación privada de servicios y el contrato de trabajo», MTSS, Madrid, pp. 281 ss.

Martín Valverde, A. (1966): «El concepto de trabajador por cuenta ajena en el Derecho Individual del Trabajo y en Derecho de la Seguridad Social», RPS, n. ${ }^{\circ} 71$, p. 79.

Mella Méndez, L. (2001): «Sobre la presunción de laboralidad STSJ Madrid de 25 enero $2000 », A L$, n. ${ }^{\circ}$, pp. 365 y ss. 
Monereo Pérez, J.L. (1996): Derechos sociales de la ciudadanía y ordenamiento laboral, Madrid Consejo Económico y Social.

- (2004): «Derechos sociales y Estado democrático social en Anton Menger», estudio preliminar a Menger: A.: El derecho al producto integro del trabajo/El Estado democrático del trabajo (El Estado socialista), Granada, Ed., Comares.

Muñoz, F. (2015): Cápsulas informativas de la Ley de emprendedores, INFO, Instituto de fomento de la Región de Murcia.

Neвот, M.J. (1999): La selección de personal, Fundación Confemetal, Madrid.

NefF, W.S. (1977): Work and Human Behavior, 2. ed, Chicago.

Podesta, C. \& Gatz, J. (1999): Guia para triunfar en el mercado de trabajo, Urano, Barcelona.

Paniagua, E. (2015): «De economía colaborativa a precariedad 2.0». El Mundo 4 de enero de 2015.

Puchol, L. (1997): La venta de sí mismo, Díaz de Santos, Madrid.

Reichel, W. (1998): Estrategias para conseguir trabajo, Drac, Madrid.

Ruiz Castillo, M.M. (2005): «El trabajo no retribuido: una importante tendencia restrictiva del Derecho del Trabajo», RDS, n.o 30, p. 17.

SaAvedra, I. (1998): Planificación y selección de recursos humanos, Pirámide, Madrid.

SÁnchez, J.C. (1997): Selección de personal. Guia práctica, Amarú, Salamanca.

Santa María La Real Fundación (2013): Memoria de actividades.

VALDÉs DAL-RÉ, F. (2012): «El trabajo prestado en el marco del voluntariado social (y II) Relaciones Laborales», n. ${ }^{\circ}$ 12, Sección Editorial, Quincena del 15 al 30 Jun. 2012, Año 28, tomo 1, Editorial. 